\title{
Prognostic Factors for Penile Cancer and Survival in Response to Multimodality Therapy
}

This article was published in the following Dove Press journal:

Research and Reports in Urology

\author{
Wichien Sirithanaphol' \\ Aumkhae Sookprasert ${ }^{2}$ \\ Ukrit Rompsaithong' \\ Pakorn Kiatsopit' \\ Kosin Wirasorn ${ }^{2}$ \\ Jarin Chindaprasirt $\mathbb{D}^{2}$ \\ 'Division of Urologic Surgery, \\ Department of Surgery, Faculty of \\ Medicine, Khon Kaen University, Khon \\ Kaen, Thailand; ${ }^{2}$ Division of Medical \\ Oncology, Department of Internal \\ Medicine, Faculty of Medicine, Khon \\ Kaen University, Khon Kaen, Thailand
}

Correspondence: Jarin Chindaprasirt

Division of Medical Oncology,

Department of Internal Medicine, Faculty

of Medicine, Khon Kaen University, Khon

Kaen 40002, Thailand

Tel +6643363664

Fax +6643202 49।

Email jarich@kku.ac.th

\begin{abstract}
Purpose: To report treatment outcomes of penile cancer in a single institution in Thailand and to identify prognostic factors for survival, highlighting the crucial role of multi-modality treatment (MMT).
\end{abstract}

Patients and Methods: Squamous cell carcinoma of penis patients who were treated at Srinagarind hospital between 2007-2015 were retrospectively analyzed. Clinical and pathological data were retrospectively reviewed. Overall survival (OS) was calculated using the Kaplan-Meier method and data were compared using the Log rank test. Cox regression analysis of factors affecting survival was conducted.

Results: A total of 70 patients were identified with a median follow-up of 69.4 months. Twenty-eight patients (40\%) presented with early-stage (stage I or II), whereas 42 patients $(60 \%)$ were stage III or IV disease. The median OS was 29.3 months (Interquartile range 10.5 months - not reached) for the entire cohort. Nodal involvement was the only factor identified from the multivariate model with the adjusted HR or 5.74 (95\% CI 2.52-13.04). For patients with stage IIIB/IV, multi-modality treatment (MMT) resulted in longer survival when compared with surgery alone (HR 0.37 ; 95\% CI $0.16-0.90$ ).

Conclusion: Patients with penile cancer in Thailand presented with younger age and more locally advanced stage. Nodal involvement is the single poor prognostic factor for OS and MMT was associated with longer survival in stage IIIB/IV disease.

Keywords: penile neoplasms, penile diseases, radiation, squamous cell

\section{Introduction}

Squamous cell carcinoma of the penis is an uncommon malignancy that accounts for only $0.4-1.7$ per 100,000 among men in Europe and the US. ${ }^{1}$ However, it is relatively more common in developing countries in Asia, Africa, and South America. ${ }^{2}$ Penile carcinoma mainly occurs in glans and commonly spreads to regional lymph nodes of which is one of the known strongest prognostic factors. ${ }^{3}$ Among the node-positive patients, the factors affecting poor survival include bilateral nodal metastases, number of node involvement, pelvic node metastasis, and extranodal extension. ${ }^{3}$

The majority of patients (in Europe and the USA) present with localized disease and could be managed by single modality treatment either surgery or radiotherapy. ${ }^{4-6}$ Nevertheless, a number of patients present with locally advanced with nodal involvement and distant metastasis. Resection of the primary tumor (penile-sparing surgery or partial/total penectomy) has long been the standard local treatment but it has been associated with significant disfigurement and impairment of quality of life. ${ }^{5,7}$ For locally advanced stage, multi-modality treatment (MMT) 
including chemotherapy, radiation, and surgery has become the recommended option. ${ }^{8,9}$

This study aimed to evaluate the clinical and treatment outcomes for penile cancer and to identify prognostic factors with a focus on those with advanced-stage treated with MMT during a contemporary 9-year period (2007 through 2015).

\section{Materials and Methods}

\section{Patients and Clinical Data}

All patients who received all or part of the treatment for penile cancer at Srinagarind Hospital, Khon Kaen University between 1 January 2007 and 31 December 2015 were included. A total of 98 patients with the diagnosis of penile cancer were identified; two patients were excluded owing to the diagnosis of squamous cell carcinoma of the urethra and leiomyosarcoma of the penis. After reviewing the medical record, patients with incomplete data $(n=14)$ and no medical record $(n=9)$ were excluded. Patients with an uncertain diagnosis of penile cancer by histology $(n=3)$ were also excluded. For the final analysis, therefore, 70 patients with squamous cell carcinoma of the penis were included.

To be classified as having received multimodality treatment (MMT), patients must have received either at least 2 out of 3 treatment modalities including surgery, radiation, and chemotherapy. The American Joint Committee on Cancer Staging Manual (eighth edition) was used to defined stages.

\section{Statistical Analyses}

Baseline and clinical characteristics were analyzed using descriptive statistics. Date of diagnosis, death or last followup were collected from medical records. Overall survival (OS) was defined as survival time from the date of penile cancer diagnosis to death from any cause. Survival analysis was performed using the Kaplan-Meier method and compared among groups and stages using the Log rank test. Univariate and multivariate Cox regression analyses of factors affecting survival were used. In univariate analysis, unadjusted hazard ratio (HR) and 95\% confidence intervals (CIs) were used to consider the strength of association. Factors with a P-value of $<0.05$ were then entered into a multivariate analysis, including ECOG performance status, lymph node involvement, metastasis at presentation, and tumor grade.

For all statistical comparisons, a p-value of less than 0.05 was considered statistically significant. All data analysis was performed using STATA software (StataCorp LP, College Station, TX, USA).

\section{Ethical Consideration}

Ethical approval was provided by the Khon Kaen University Faculty of Medicine Ethics Committee as instituted by the Declaration of Helsinki (Number HE581333). The patient consent to review the medical record was not required by the committee due to the retrospective nature of the study. All the data was anonymized and maintained with confidentiality.

\section{Results}

\section{Clinical and Demographic Characteristics}

The median age was 54.2 years (range; $25-89$ years). Most of the patients presented at age 40-49 years and 50-59 years respectively. Twenty-eight patients $(40 \%)$ were stage I or II and 42 patients $(60 \%)$ were stage III or IV. The numbers of patients in stages I, II, III, and IV were 5, 23, 15, and 27, respectively. Eight patients (11.6\%) had

Table I Demographics and Clinical Characteristics of 70 Penile Cancer Patients

\begin{tabular}{|c|c|c|c|}
\hline & $\begin{array}{l}\text { Stage } I / I I \\
(n=28)\end{array}$ & $\begin{array}{l}\text { Stage III/ } \\
\text { IV }(n=42)\end{array}$ & $\begin{array}{l}\text { Total } \\
(n=70)\end{array}$ \\
\hline \multicolumn{4}{|l|}{ Age at diagnosis (year) } \\
\hline Mean (SD) & $53.9(13.6)$ & $54.5(13.8)$ & $54.2(13.6)$ \\
\hline Range & $32-83$ & $25-89$ & $25-89$ \\
\hline \multicolumn{4}{|l|}{$\begin{array}{l}\text { Presenting symptoms, } \\
n(\%)\end{array}$} \\
\hline Penile mass & $20(80.0)$ & $20(57.2)$ & $40(66.7)$ \\
\hline Penile ulcer & $4(16.0)$ & $8(22.9)$ & $12(20.0)$ \\
\hline Groin mass & 0 & $5(14.3)$ & $5(8.3)$ \\
\hline Penile pain/itching & I (4.0) & I (2.8) & $2(3.3)$ \\
\hline Dysuria & 0 & $\mathrm{I}(2.8)$ & I (I.7) \\
\hline \multicolumn{4}{|l|}{ Location, n (\%) } \\
\hline Prepuce & 0 & $2(5.0)$ & $2(2.9)$ \\
\hline Tip of penis & $27(96.4)$ & $37(92.5)$ & $64(94.2)$ \\
\hline Shaft & I (3.6) & I (2.5) & $2(2.9)$ \\
\hline \multicolumn{4}{|l|}{ Tumor grade, n (\%) } \\
\hline Grade I & $25(96.1)$ & $27(73.0)$ & $52(82.5)$ \\
\hline Grade 2/3 & I (3.9) & $10(27.0)$ & II (I7.5) \\
\hline \multicolumn{4}{|l|}{$\begin{array}{l}\text { ECOG performance } \\
\text { status, } n(\%)\end{array}$} \\
\hline $0-1$ & $28(100)$ & $38(90.5)$ & $66(82.9)$ \\
\hline$\geq 2$ & 0 & $4(9.5)$ & $4(5.7)$ \\
\hline $\begin{array}{l}\text { Time from presentation } \\
\text { to diagnosis (months), } \\
\text { median (range) }\end{array}$ & $2.6(0-40.3)$ & I.4 (0-53.7) & $2.1(0-53.7)$ \\
\hline
\end{tabular}

Abbreviation: ECOG, Eastern Cooperative Oncology Group. 
metastatic disease. Clinical and demographical characteristics are listed in Table 1.

Most of the patients presented with penile mass or ulcer; $96 \%$ in stage I/II and $80 \%$ in stage III/IV. Groin mass was the presenting symptom in $14 \%$ of stage III/ IV patients. Tip of the penis was the most common location of the tumor both in stage I/II and stage III/ IV groups. Almost all patients in this cohort had a good performance status. There was more moderately (grade 2) or poorly (grade 3) differentiated tumor in the stage III/IV group (27.9\%) compared to stage I/II group $(3.9 \%)$. Median time from presentation to diagnosis was 2.1 months.

\section{Overall Survival and Prognostic Factors}

The median follow-up duration was 69.4 months (range, 1.2-89.4 months) for the entire cohort and the median overall survival (OS) was 29.3 months $(95 \% \mathrm{CI} ; 15.0$ 63.6). The 1-year, 3-year, and 5-year survival rate were $72.5 \%$ (60.3-81.5), 46.4\% (34.3-57.6), 39.03\% (27.250.7), respectively. Patients with nodal involvement had a significantly shorter survival; 13.8 vs 82.0 months, $\mathrm{p}=<0.001$ (Table 2). Similarly, those with metastasis at presentation had a worse prognosis of 11.2 vs 47.2 months, $p=0.001$ (Figure 1A and B), with only one patient survived more than 2 years. Moreover, Eastern Cooperative Oncology Group (ECOG) performance status and histological grade are also significant prognostic factors with HR of $2.99(\mathrm{p}=0.002)$ and $2.15(\mathrm{p}=0.045)$, respectively (Figure 1C and D). A trend towards better survival was seen in younger patients $(\mathrm{p}=0.55)$.

The results of multivariate regression analysis for survival which ECOG performance status, nodal involvement, metastasis at diagnosis, and histological grading were entered, are presented in Table 2. In the final survival model, nodal involvement was the only significant predictor of OS. The adjusted hazard ratios $(95 \%$ confidence interval was $5.74(2.52,13.04)$. There was no significant violation of the proportional hazards assumption.

\section{Treatment Modalities}

Treatment details are listed in Table 3; 29 patients (41\%) underwent surgery alone, while 41 patients (59\%) received multi-modality treatment(MMT). In general, patients either assigned to receive surgery alone or MMT principally by staging and willingness to receive radiation or chemotherapy. It was clearly noted that the MMT group covered a greater proportion of patients with stage III and IV disease.

Surgical resection was performed in $95 \%$ of patients; partial penectomy was done in 21 patients $(72 \%)$ in the surgery alone group vs 17 patients (41\%) in the MMT group. Thirty-one patients (75\%)

Table 2 Univariate and Multivariate Analysis of Overall Survival According to Clinical and Pathological Characteristics

\begin{tabular}{|c|c|c|c|c|c|}
\hline \multirow[t]{2}{*}{ Variables } & \multirow[t]{2}{*}{ Median Survival (Months) } & \multicolumn{2}{|l|}{ Univariate } & \multicolumn{2}{|l|}{ Multivariate } \\
\hline & & Unadjusted HR & $95 \% \mathrm{Cl}$ & Adjusted HR & $95 \% \mathrm{Cl}$ \\
\hline \multicolumn{6}{|l|}{ Age (year) } \\
\hline$<50$ & 29.3 & & & & \\
\hline$\geq 50$ & 19.0 & 1.21 & $0.65-2.23$ & & \\
\hline \multicolumn{6}{|l|}{ ECOG } \\
\hline 0 & 47.2 & & & & \\
\hline$\geq 1$ & 10.5 & $2.99 *$ & $1.52-5.89$ & 2.13 & $0.92-4.95$ \\
\hline \multicolumn{6}{|c|}{ Nodal involvement } \\
\hline Positive & 13.8 & $5.15^{*}$ & $2.49-10.64$ & $5.74 *$ & $2.52-13.04$ \\
\hline Negative & 82 & & & & \\
\hline \multicolumn{6}{|l|}{ Metastasis } \\
\hline No & 47.2 & & & & \\
\hline Yes & 11.2 & $3.88 *$ & I.74-8.64 & 1.54 & $0.64-3.67$ \\
\hline \multicolumn{6}{|l|}{ Grade } \\
\hline Grade I & 45.4 & & & & \\
\hline Grade $2 / 3$ & 10.5 & $2.15^{*}$ & $1.02-4.56$ & 0.89 & $0.38-2.10$ \\
\hline
\end{tabular}

Note: *Statistically significant. 

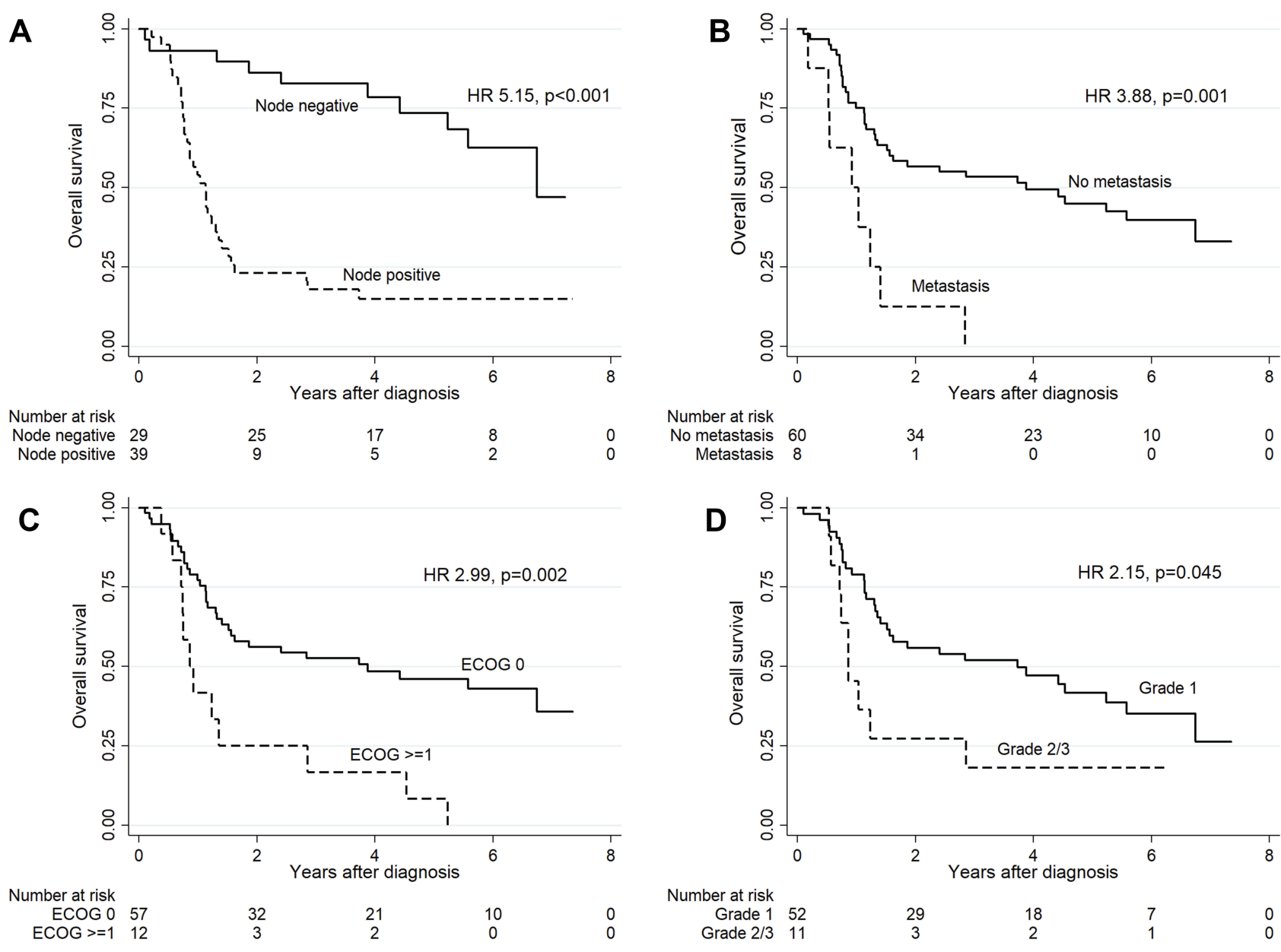

Figure I Survival according to prognostic factors.

Notes: (A) Nodal involvement. (B) Metastasis. (C) ECOG performance status. (D) Histological grading.

in the MMT group received radiation with the median dose of 5000 cGy.

Chemotherapy was administered in 32 patients $(78 \%)$ in the MMT group and the most prescribed regimen was cisplatin plus fluorouracil. A median number of cycles of chemotherapy was 4 (range 1-7). Twenty-two patients $(53 \%)$ received radiation combined with chemotherapy.

\section{Survival Characteristics of Stage IIIB/IV Disease}

Patients in the MMT group with stage IIIB and IV had a median OS of 13.8 months compared to surgery alone group of 8.7 months, respectively. No patients in the surgery alone group survived more than 2 years. MMT was associated with significantly longer survival when compared with surgery alone in patients with stage IIIB/ IV disease with a hazard ratio of 0.37 (95\% CI 0.16-0.90; p-value 0.029) as shown in Figure 2.

\section{Discussion}

This retrospective study of penile cancer revealed a poor survival outcome (median overall survival 29.3 months) and the most important poor prognostic factor for overall survival was nodal involvement. Moreover, this study highlighted the survival benefit of multi-modality treatment (MMT) for the locally advanced disease compared to surgery alone.

At presentation, patients in this cohort were younger than previously reported data; the median age was 54.2 years compared to 60-67 years in reports from the US and UK. ${ }^{4,5,10}$ Patients presented with a more advanced stage in this series with a higher proportion of node-positive disease $(48 \%)$ compared to only $15 \%$ from a study by Veeratterapillay et al. ${ }^{5}$ The aggressiveness of the tumor and the delay in patients' awareness could explain this high positive nodal disease in Thailand. However, when compared with the report from Africa, the population in 
Table 3 Treatment Modality

\begin{tabular}{|c|c|c|c|}
\hline Treatment & $\begin{array}{l}\text { Surgery } \\
(n=29)\end{array}$ & $\begin{array}{l}\text { MMT } \\
(n=4 I)\end{array}$ & $\begin{array}{l}\text { Total } \\
(n=70)\end{array}$ \\
\hline \multicolumn{4}{|l|}{ Stage, n (\%) } \\
\hline Stage I/II & $20(69.0)$ & $8(19.5)$ & $28(40.0)$ \\
\hline Stage III/IV & $9(31.0)$ & $33(80.5)$ & $42(60.0)$ \\
\hline \multicolumn{4}{|l|}{ Surgery, n (\%) } \\
\hline No & 0 & $4(9.8)$ & $4(5.7)$ \\
\hline Wide excision & $5(17.2)$ & $6(14.6)$ & II (I5.7) \\
\hline Partial penectomy & $21(72.4)$ & $17(4 \mid .5)$ & $38(54.3)$ \\
\hline Radical penectomy & $3(10.4)$ & $14(34.1)$ & $17(24.3)$ \\
\hline \multicolumn{4}{|l|}{$\begin{array}{l}\text { Lymph node dissection, } \\
\text { n (\%) }\end{array}$} \\
\hline No & $19(65.5)$ & $20(48.8)$ & $39(55.7)$ \\
\hline Yes & $10(34.5)$ & $21(5 \mid .2)$ & $31(44.3)$ \\
\hline \multicolumn{4}{|l|}{ Radiation, n (\%) } \\
\hline No & $29(100)$ & $10(24.4)$ & $39(55.7)$ \\
\hline Yes & 0 & $31(75.6)$ & $31(44.3)$ \\
\hline \multicolumn{4}{|l|}{ Chemotherapy, n (\%) } \\
\hline No & $29(100)$ & $9(21.9)$ & $38(54.3)$ \\
\hline Cisplatin/Fluorouracil & 0 & $24(58.5)$ & $24(34.3)$ \\
\hline Methotrexate/ & 0 & I (2.4) & I (I.4) \\
\hline \multicolumn{4}{|l|}{ Fluorouracil } \\
\hline Carboplatin/Paclitaxel & 0 & I (2.4) & I (I.4) \\
\hline TIP regimen & 0 & I (2.4) & I (I.4) \\
\hline Platinum single agent & 0 & $5(12.2)$ & $5(7.2)$ \\
\hline
\end{tabular}

this cohort was slightly older and less advanced. In a retrospective study from Tanzania, the median age was 47 years and $65 \%$ of the patients were node-positive. ${ }^{11}$

According to several reports, increasing nodal status is an important factor for predicting poor prognosis in penile

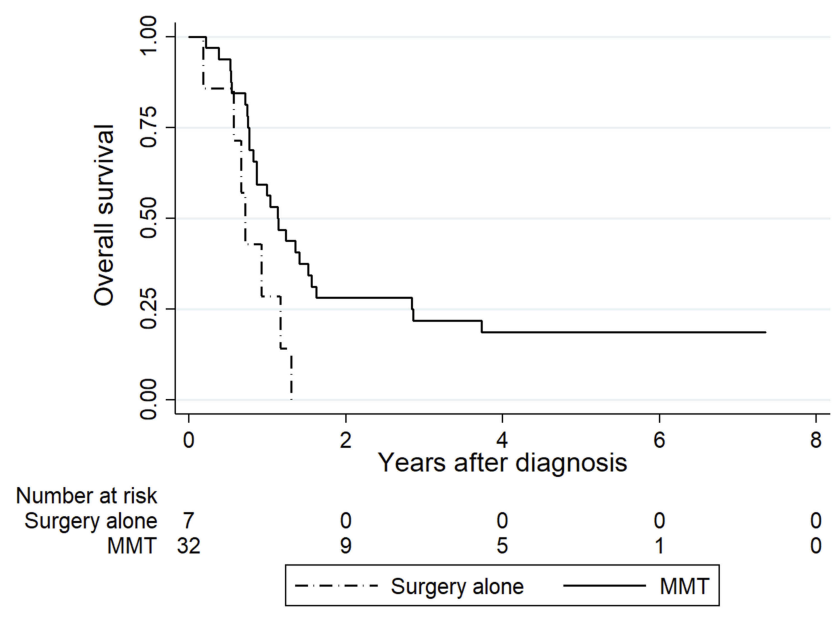

Figure 2 Kaplan-Meier estimates of OS for the stage IIIB/IV disease $(n=39)$ by treatment modalities. cancer. ${ }^{3-5}$ With the increase of the nodal count, the worsening of the survival rate as reported by Pandey et al in nodepositive penile cancer patients. ${ }^{3}$ In this cohort, the number of nodal involvement could not be retrieved but the association between nodal involvement and poor survival was also displayed by the multivariate analysis. Moreover, ECOG performance status was found to be associated with poor survival, similar to the report by Pond et al. ${ }^{12}$

For locally advanced disease, multi-modality treatment has been recommended over surgery alone. Treatment with a combination of neoadjuvant chemotherapy followed by surgery has been studied with some long-term responses. ${ }^{13-15}$ Cisplatin-based combination chemotherapy was applied to almost all patients, similar to other reported studies. ${ }^{16,17}$ Concurrent treatment with chemotherapy and radiation has also been reported with the dismal outcome (OS of 6.9 months). ${ }^{16}$ The outcome of stage IIIB/IV treated with MMT in this series was slightly better than previously reported data with the overall survival of 13.8 months. ${ }^{16}$ Zhang et al reported the surgical treatment of advanced penile cancer with resection of the lesion and flap repair. ${ }^{18}$ This technique could help improve quality of life but the survival was only 9 months (4-13 months). Multimodality treatment with a combination of chemotherapy, radiation, and surgery has been reported with good outcomes in recurrent disease and it is the recommended treatment option for locally advanced disease. ${ }^{8,9}$ This study confirmed the survival advantage of MMT over surgery alone in advanced stage penile cancer.

This was the first large study in Thai patients. However, the data and statistical significance in this study should be interpreted with caution. There were biases due to the nature of retrospective analyses and data from a single center. There was a variation in terms of surgical technique, nodal dissection, radiation dosage and planning, and also the use of chemotherapy regimen and adding the treatment modality to the analysis would result in instability of the model. And there was no data regarding HPV status among the patients but presumably positive.

\section{Conclusion}

In summary, patients with penile cancer in Thailand presented with younger age and more locally advanced stage. Despite the limitations, this study highlighted the crucial role of multi-modality treatment for stage IIIB and IV disease, and nodal involvement is the single poor prognostic factor for OS. 


\section{Disclosure}

The authors report no conflicts of interest in this work

\section{References}

1. Christodoulidou M, Sahdev V, Houssein S, Muneer A. Epidemiology of penile cancer. Curr Probl Cancer. 2015;39(3):126-136. doi:10.10 16/j.currproblcancer.2015.03.010

2. Bleeker MC, Heideman DA, Snijders PJ, Horenblas S, Dillner J, Meijer CJ. Penile cancer: epidemiology, pathogenesis and prevention. World J Urol. 2009;27(2):141-150. doi:10.1007/s00345-008-0302-z

3. Pandey D, Mahajan V, Kannan RR. Prognostic factors in node-positive carcinoma of the penis. $J$ Surg Oncol. 2006;93(2):133-138. doi: $10.1002 /$ jso. 20414

4. Burt LM, Shrieve DC, Tward JD. Stage presentation, care patterns, and treatment outcomes for squamous cell carcinoma of the penis. Int J Radiat Oncol Biol Phys. 2014;88(1):94-100. doi:10.1016/j. ijrobp.2013.08.013

5. Veeratterapillay R, Teo L, Asterling S, Greene D. Oncologic outcomes of penile cancer treatment at a UK supraregional center. Urology. 2015;85(5):1097-1103. doi:10.1016/j.urology.2014.11.048

6. Korzeniowski MA, Crook JM. Contemporary role of radiotherapy in the management of penile cancer. Transl Androl Urol. 2017;6 (5):855-867. doi:10.21037/tau.2017.07.02

7. Martins FE, Rodrigues RN, Lopes TM. Organ-preserving surgery for penile carcinoma. Adv Urol. 2008;2008:1-7. doi:10.1155/2008/634216

8. National Comprehensive Cancer Network; 2019 Penile Cancer (Version 1.2019). Available from: https://www.nccn.org/profes sionals/physician_gls/pdf/penile.pdf. Accessed April 19, 2019.

9. Pagliaro LC, Crook J. Multimodality therapy in penile cancer: when and which treatments? World J Urol. 2009;27(2):221-225. doi:10.10 07/s00345-008-0310-z
10. Mistry T, Jones RW, Dannatt E, Prasad KK, Stockdale AD. A 10-year retrospective audit of penile cancer management in the UK. BJU Int. 2007;100(6):1277-1281. doi:10.1111/j.1464-410X.2007.07168.x

11. Chalya PL, Rambau PF, Masalu N, Simbila S. Ten-year surgical expereinces with penile cancer at a tertiary care hospital in northwestern Tanzania: a retrospective study of 236 patients. World J Sug Oncol. 2015;13:71. doi:10.1186/s12957-015-0482-0

12. Pond GR, Di Lorenzo G, Necchi A, et al. Prognostic risk stratification derived from individual patient level data for men with advanced penile squamous cell carcinoma receiving first-line systemic therapy. Urol Oncol. 2014;32(4):501-508. doi:10.1016/j.urolonc.2013.10.007

13. Hakenberg OW, Protzel C. Chemotherapy in penile cancer. Ther $A d v$ Urol. 2012;4(3):133-138. doi:10.1177/1756287212441235

14. Bermejo C, Busby JE, Spiess PE, Heller L, Pagliaro LC, Pettaway CA. Neoadjuvant chemotherapy followed by aggressive surgical consolidation for metastatic penile squamous cell carcinoma. J Urol. 2007;177(4):1335-1338. doi:10.1016/j.juro.2006. 11.038

15. Pagliaro LC, Williams DL, Daliani D, et al. Neoadjuvant paclitaxel, ifosfamide, and cisplatin chemotherapy for metastatic penile cancer: a Phase II study. J Clin Oncol. 2010;28(24):3851-3857. doi:10.1200/ JCO.2010.29.5477

16. Pond GR, Milowsky MI, Kolinsky MP, et al. Concurrent chemoradiotherapy for men with locally advanced penile squamous cell carcinoma. Clin Genitourin Cancer. 2014;12(6):440-446. doi:10.10 16/j.clgc.2014.03.009

17. Pettaway CA, Pagliaro L, Theodore C, Haas G. Treatment of visceral, unresectable, or bulky/unresectable regional metastases of penile cancer. Urology. 2010;76(2 Suppl 1):S58-S65. doi:10.1016/j.urology. 2010.03.082

18. Zhang K, Wan X, Xu H, et al. Surgical treatment of advanced penile cancer. J Cancer Res Clin Oncol. 2017;143(9):1865-1870. doi:10. 1007/s00432-017-2435-1
Research and Reports in Urology

\section{Publish your work in this journal}

Research and Reports in Urology is an international, peer-reviewed, open access journal publishing original research, reports, editorials, reviews and commentaries on all aspects of adult and pediatric urology in the clinic and laboratory including the following topics: Pathology, pathophysiology of urological disease; Investigation and treatment of urological disease; Pharmacology of drugs used for the treatment of urological disease. The manuscript management system is completely online and includes a very quick and fair peer-review system, which is all easy to use. Visit http://www.dovepress.com/ testimonials.php to read real quotes from published authors. 